\title{
Textural Characteristics and Friction Properties of Facial Tissues
}

\author{
Kei Shibata $^{1) *}$, Naoya Yamai ${ }^{11}$, Takeshi Yamaguchi ${ }^{1,2)}$, Hidenori Yorozu ${ }^{3)}$, Shuta Yasui ${ }^{3)}$, Wataru Tanabe ${ }^{4)}$ \\ and Kazuo Hokkirigawa ${ }^{1)}$ \\ ${ }^{1)}$ Graduate School of Engineering, Tohoku University, 6-6-01 Aramaki Aza-Aoba, Aoba-ku, Sendai 980-8579, Japan \\ ${ }^{2)}$ Graduate School of Biomedical Engineering, Tohoku University, 6-6-01 Aramaki Aza-Aoba, Aoba-ku, Sendai 980-8579, Japan \\ ${ }^{3)}$ Daio Paper Corporation, Iidabashi Grand Bloom, 10-2 Fujimi 2-chome, Chiyoda-ku, Tokyo 102-0071, Japan \\ ${ }^{4)}$ Ohmiya Paper Corporation, 329 Nonaka, Fujinomiya 418-0038, Japan \\ *Corresponding author: Kei Shibata (shibata@gdl.mech.tohoku.ac.jp)
}

Manuscript received 1 June 2017; accepted 3 August 2017; published 15 October 2017

\begin{abstract}
In the current study, we conducted sensory tests for facial tissues that are commercially available in Japan, and we also tested the friction generated by the rubbing of these tissues on an artificial skin model. Using these results, we investigated the factors affecting the textural characteristics of the facial tissues. The tissue sample which contained a moisturizing agent had the highest evaluation score among the samples. Mean friction coefficient decreased as the sliding velocity decreased for low normal loads. The tissue samples which contained moisturizing agents had the low friction coefficients. From the multiple regression analysis to obtain the highest value of the adjusted coefficient of determination, the mean friction coefficient for a normal load of $0.49 \mathrm{~N}$ and a sliding velocity of $1 \mathrm{~mm} / \mathrm{s}$ was the only parameter surprisingly that could be used to predict the evaluation scores; specifically, there was a negative correlation between the mean friction coefficient and the scores. In order to reduce the friction, one should seek to increase the moisture content of a facial tissue or decrease the tensile strength perpendicular to the fiber direction in dry facial tissues. Increasing the elastic modulus and surface roughness and decreasing the fiber diameter were effective methods for reducing the friction coefficient of facial tissues that did not contain moisturizing agents.
\end{abstract}

\section{Keywords}

facial tissue, textural characteristic, friction, artificial skin, regression analysis

\section{Introduction}

Facial tissues are widely used for a variety of aesthetic and hygienic purposes, including blowing noses, wiping mouths, wiping away cosmetics, and wiping off table surfaces. In Japan, several kinds of facial tissues have been made available by paper-manufacturing companies. A lot of these tissues have been modified in some way so as to give them characteristics that set them apart from ordinary facial tissues; this results in tissue-product types that include fragrant facial tissues, moisturizing tissues, and luxury tissues. Facial tissues are made from wood pulp, which is obtained from both hardwood and softwood. Hardwoods are, in general, more complex and heterogeneous in structure than softwoods, and they have shorter fiber cells than softwoods [1]. In addition, softwood fibers are known to be stronger than hardwood fibers [1]. Facial tissues produced by mixing these two types of wood pulp at certain rates allow for desired properties, such as softness and strength, to be obtained. In a paper-manufacturing process, paper is peeled off of a rotating dryer by a doctor blade, resulting in fine crepes being produced on the tissue surfaces. These crepes affect the thickness, softness, and water absorption of the tissues. Sometimes, an augmenting agent or a softening agent is used to retain the strength of a tissue under moist conditions and to improve its softness, respectively. During the manufacturing process, the blend ratio of the wood pulp, rate of crepe, and composition of these agents are determined by the concept of the final product that will be produced. As such, factors such as texture sensation or softness also depend on the type of facial tissue that is produced.

Facial tissues are consumer-oriented products. When making a purchasing decision for facial tissues, consumers use several characteristics: wiping performance, strength, usability, and comfort [2,3]. When considering using these tissues for wiping away detritus, consumers look at their ability to clean cosmetics, perspiration, bodily fluids, and food and drink. Therefore, it is clear that a tissue's ability to absorb water and oil is important, and tearing or creation of unwanted residues 
Table 1 Mechanical properties of facial tissue samples

\begin{tabular}{|c|c|c|c|c|c|c|c|c|c|c|}
\hline Sample & A & $\mathrm{B}$ & $\mathrm{C}$ & $\mathrm{D}$ & E & $\mathrm{F}$ & G & $\mathrm{H}$ & $\mathrm{I}$ & $\mathrm{J}$ \\
\hline Moisture content $\alpha, \%$ & 4.4 & 4.5 & 3.5 & 4.0 & 7.0 & 3.5 & 4.9 & 16.1 & 10.2 & 13.2 \\
\hline Density $\rho, \mathrm{kg} / \mathrm{m}^{3}$ & 186 & 171 & 220 & 214 & 140 & 187 & 183 & 234 & 179 & 236 \\
\hline Paper thickness $t, \mu \mathrm{m}$ & 142 & 190 & 129 & 101 & 205 & 129 & 119 & 145 & 174 & 123 \\
\hline Tensile strength along to fiber direction in dry $\sigma_{\mathrm{d} a} \mathrm{~N}$ & 3.48 & 2.85 & 3.47 & 5.24 & 3.09 & 3.54 & 3.67 & 2.25 & 3.40 & 3.10 \\
\hline Tensile strength perpendicular to fiber direction in dry $\sigma_{\mathrm{dp},} \mathrm{N}$ & 0.90 & 1.02 & 1.42 & 1.61 & 0.84 & 1.52 & 1.33 & 0.80 & 0.51 & 0.73 \\
\hline Tensile strength perpendicular to fiber direction in wet $\sigma_{\mathrm{wp}}, \mathrm{N}$ & 0.30 & 0.35 & 0.36 & 0.37 & 0.30 & 0.41 & 0.29 & 0.50 & 0.32 & 0.34 \\
\hline Softness $s, \times 10^{-2} \mathrm{~N}$ & 1.14 & 1.15 & 1.24 & 1.06 & 0.91 & 0.88 & 0.96 & 0.88 & 0.73 & 0.90 \\
\hline Surface roughness $R_{a}, \mu \mathrm{m}$ & 10.5 & 8.61 & 10.04 & 8.07 & 10.45 & 10.23 & 9.20 & 10.01 & 8.48 & 9.73 \\
\hline Surface waviness $W_{a} \mu \mathrm{m}$ & 12.95 & 8.78 & 8.53 & 7.25 & 15.89 & 8.67 & 8.50 & 14.95 & 12.45 & 9.60 \\
\hline Compressive elastic modulus $E, \mathrm{kPa}$ & 1.58 & 1.80 & 1.19 & 0.94 & 1.92 & 1.32 & 1.13 & 0.78 & 1.31 & 1.61 \\
\hline Mean fiber diameter $d_{\mathrm{m}}, \mu \mathrm{m}$ & 18.4 & 17.1 & 16.0 & 18.5 & 24.1 & 21.7 & 20.7 & 23.5 & 14.7 & 20.8 \\
\hline
\end{tabular}

must be avoided. Facial tissues ordinarily possess a certain amount of strength that allows them to withstand tearing when they are wet; as such, it is difficult for tissues to be broken apart when in water; this is why, unlike toilet paper, manufacturers recommend that facial tissues are not disposed of by flushing them down the toilets. Usability is also important consideration, and it relates to how easily a facial tissue can to be removed from its container and separated from other tissues. Finally, texture of a facial tissue is an important consideration as it affects user's comfort [3].

Textiles, including facial tissues, are often evaluated with a variety of sensory tests [4-7]. Cho et al. [8] investigated the sound and touch sensation of fabrics using a semantic differential (SD) technique. They concluded that the sound and touch sensations can mostly be expressed by physical properties of the fabrics, which showed a relatively high coefficient of determination between those. Furthermore, they noted that these results could be used for the development of better textile fabrics that would satisfy consumers more. Na et al. [9] investigated the handle and sensibility of woven silk fabrics used in neckties using the SD technique; they did this in order to determine whether there was a relationship between the handle and sensibility of woven silk fabrics and consumers' purchasing preferences. They made a diagram (distribution map) of the type of silk fabric as a function of the sensibilities, and they concluded that the diagram would be useful when offering basic data for textile design or fabrication to satisfy consumer needs.

Such sensory tests are expected to be effective for evaluating the textural characteristics of facial tissues. In addition, investigating the factors that affect these characteristics is important, as it could allow for new products and surface treatments to be designed that are better preferred by consumers [3]. However, only a few papers have investigated what factors affect the textural characteristics of facial tissues. Mechanical and surface properties of facial tissues are considered to be possible factors that affect the textural characteristics. As we have explained, the facial tissues are often used to wipe away undesired item from a human skin; facial tissues can therefore be regarded as tribomaterials. When evaluating their textural characteristics, their friction properties should be considered.

As a result, we conducted sensory tests for facial tissues that are commercially available in Japan, and we also tested the friction generated by the rubbing of these tissues on an artificial skin model. Using these results, we investigated the factors affecting the textural characteristics of the facial tissues.

\section{Experimental details}

\subsection{Facial tissue samples}

We used ten different kinds of facial tissues commercially available in Japan as samples in our experiment. Table 1 lists the mechanical properties of each sample. Each characteristic of the tissues listed in the table was measured five times, and the mean values for each characteristic are given in the table. We tested the moisture content, thickness, tensile strength (when the tissue was both dry and wet), and softness; the tests we conducted were based on the Japanese Industry Standard (JIS) tests [10-13]. The thickness of the tissues was measured using two sheets of tissues, because facial tissues in Japan are sold in two-ply sheets. The moisture content was calculated using the following Eq. [12]:

$$
\alpha=\frac{m_{\mathrm{b}}-m_{\mathrm{a}}}{m_{\mathrm{b}}} \cdot 100
$$

where $\alpha$ is the moisture content (\%), $m_{\mathrm{b}}$ is the weight of a sheet of tissue before drying (g), $m_{\mathrm{a}}$ is the weight of a sheet after drying $(\mathrm{g})$. The drying temperature and time were $105^{\circ} \mathrm{C}$ and 60 min, respectively. Samples H, I, and J included moisturizing agents, such as glycerin; therefore, the moisture contents of these samples were expected to be greater than the other samples. The tensile strength along to the fiber direction in dry tissues was expected to be greater than the tensile strength perpendicular to the fiber direction in these tissues. In addition, the tensile strength of wet tissues was expected to be lower than of dry ones. The softness indicates a reactive force of a pressure plate which presses the center of the tissue samples, based on the Japanese Standards Association [13]. The compressive elastic modulus was measured using a thin stainless plate, weights, and a laser displacement meter. Ten sheets of tissues were lapped; the weights were loaded with the plate at three minutes interval. Then, a stress-strain curve was obtained.

Figure 1 shows scanning electron microscopy images of the surfaces and cross sections of samples $C, G, H$, and I. The diameters and lengths of the fibers were different between the four samples. The ways in which the fibers were entangled or deformed were also different between the four.

\subsection{Sensory testing}

We conducted sensory tests on a large number of samples by using the SD technique [14]. Sample A was defined as the standard against which the other samples were compared. Table 2 demonstrates an evaluation panel, which was used during the sensory tests. A subject compares a chosen sample with sample A and provides a score of between 1 and $7 ; 1$ is given if 
(a)
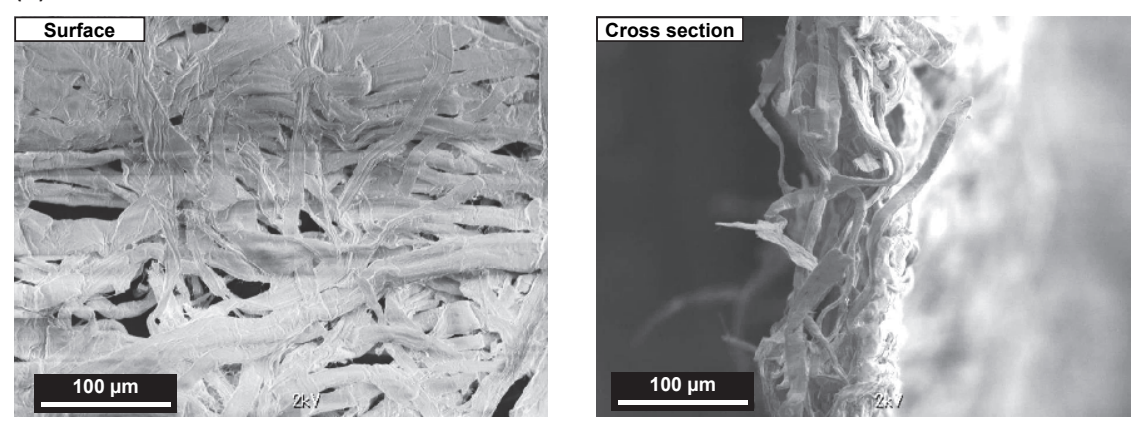

(b)
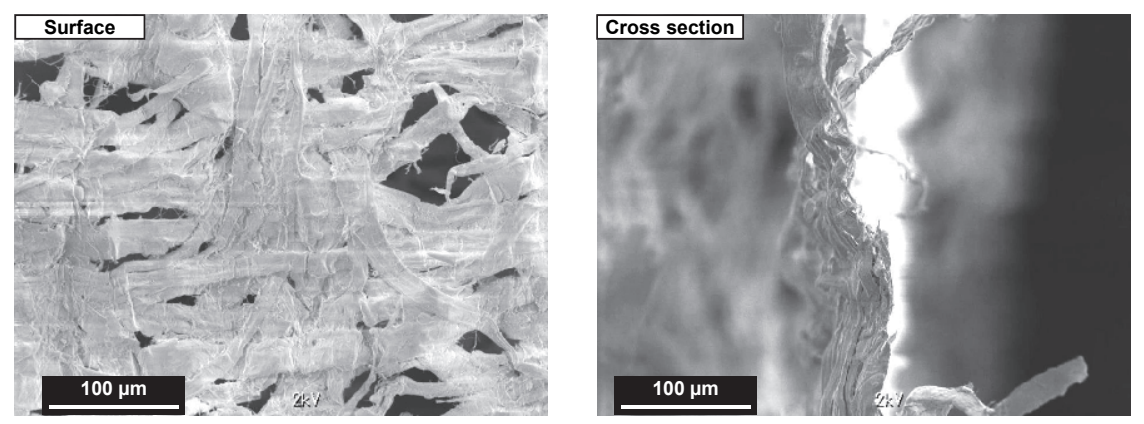

(c)
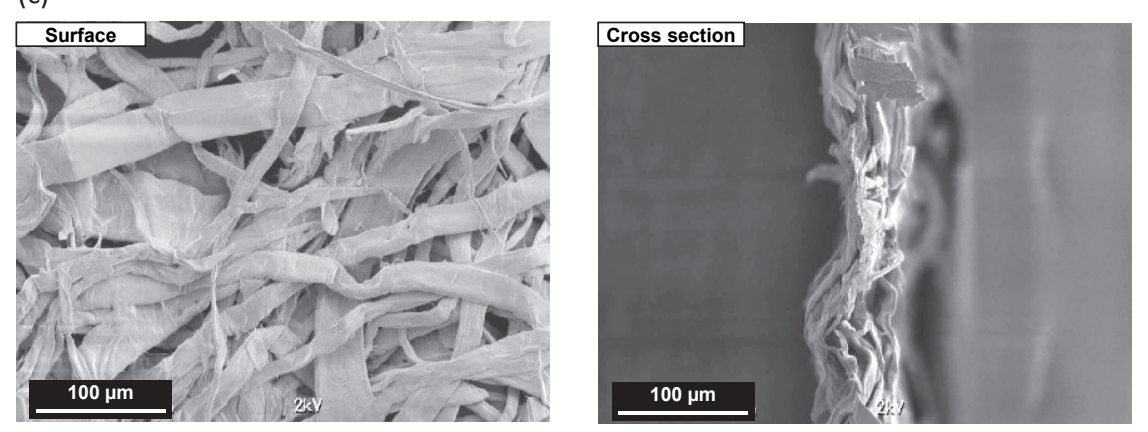

(d)
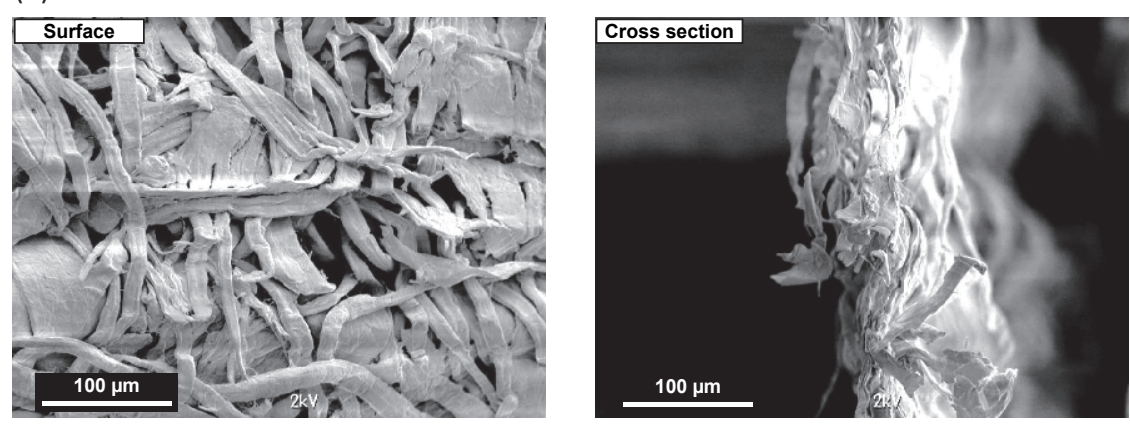

Fig. 1 Scanning electron microscope images of surfaces and cross sections of tissue samples (a) C, (b) G, (c) H, and (d) I

Table 2 Evaluation panel

\begin{tabular}{|c|c|c|c|c|c|c|}
\hline Quite bad & Bad & Slightly bad & $\begin{array}{c}\text { Same as } \\
\text { standard sample }\end{array}$ & Slightly good & Good & Quite good \\
\hline $\begin{array}{c}1 \text { point } \\
\text { (lowest) }\end{array}$ & 2 point & 3 point & 4 point & 5 point & 6 point & $\begin{array}{c}7 \text { point } \\
\text { (highest) }\end{array}$ \\
\hline
\end{tabular}

the subject feels the chosen sample is significantly worse than A, while 7 is given when the sample is felt to be significantly better. The experimenters were instructed to decide the score according to just only whether they prefer the sample or not.
The evaluation panel was presented to the subject on a desk at which he/she was seated. The following protocol was used in the testing process:

(a) The details of the sensory test are explained to a subject. 
(b) The subject takes a rest $(15 \mathrm{~min})$ that includes the explanation time of the protocol (a).

(c) The subject touches sample A and evaluates its textural characteristics, understanding that it is used as the standard sample.

(d) The subject then touches three other randomly selected samples and evaluates them.

(e) The skin that touched the sample is cleaned with a handkerchief or towel.

(f) Steps (b)-(e) are repeated three times, i.e., three different sets of three samples are tested.

The nine samples, aside from sample A, were put into three groups at random. In addition, the order in which the groups were evaluated was randomized. Figure 2 shows an example of the order in which the samples were evaluated. In order to remove any paper residue or moisturizing agents remaining on the subject's skin, the skin that touched the samples was cleaned with a handkerchief or towel. An alcohol cleaning (ethanol) was not allowed because it may remove natural oil in their skin. The cleaning with a dried handkerchief or towel is usually used and can keep an initial surface state in activities of daily living. Within each individual group, rescoring was allowed, but the samples could not be touched again. The time used for these evaluations was unlimited.

24 healthy young adults (14 males and 10 females) participated in the sensory testing. The mean age of the subjects was $23.3 \pm 1.1$ years. Prior to their participation, we obtained each subject's informed consent. In order to avoid a visual influence on the evaluation, a blank white box was used for every specimen, as shown in Fig. 3. The subjects were instructed to touch with their nose or hands and so on which were selfselected by them. The samples were put in the room that was to be used for testing 24 hours prior to testing. The temperature

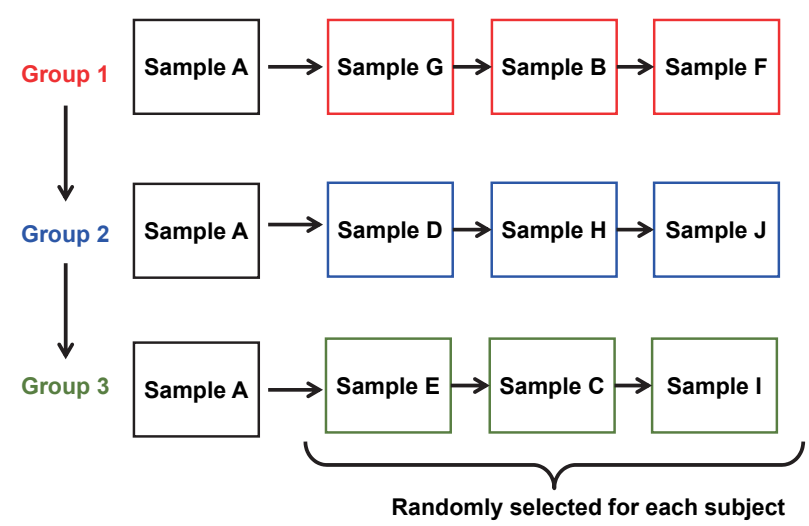

Fig. 2 An example of evaluation order of tissue samples

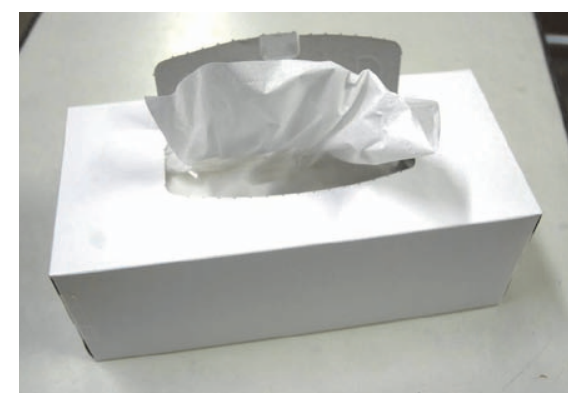

Fig. 3 Image of a blank white box of the room was maintained at $25 \pm 1^{\circ} \mathrm{C}$ and the humidity of $20 \pm 1 \%$; these were used, as they are typical room conditions that one would find in winter in Japan. When calculating the results, the mean value of the evaluations by the 24 subjects was calculated for each sample.

\subsection{Friction testing}

2.3.1 Selection of friction test conditions

Appropriate ranges of the sliding velocities and normal loads had to be selected for the friction tests; we therefore measured the movement velocities of the subject's fingers and forces with which the subject's fingers pressed the tested samples (hereafter referred to as the pressing force) during the sensory tests prior to conducting the friction tests.

Figure 4 shows the experiment image of measurement of the movement velocities of subject's fingers and the forces. A wearable contact force sensor (Haplog, Kato Tech Co.,Ltd.) was attached onto the index finger and thumb of the subject's hand. This sensor was able to measure the contact force applied by a finger onto a surface of object, and it can also measure acceleration. Five of 24 subjects were randomly chosen and asked to touch a sample as the same fashion of the sensory tests while wearing the device, after they had tested sample A.

Table 3 lists the movement velocities and pressing forces of five subjects. The mean movement velocities and pressing forces were $5.51 \mathrm{~mm} / \mathrm{s}$ and $0.53 \mathrm{~N}$, respectively. We decided that the friction tests should be conducted in the ranges near these values.

\subsubsection{Friction test conditions}

A linear-motion friction tester (Tribo-Master type: $\mu \mathrm{v} 1000$, Trinity Lab Inc.) was used for friction tests, as shown in Fig. 5. An artificial skin model (Finger Model detector, Trinity Lab Inc.) was used as a counterpart specimen of friction pairs, which was made from urethane. The skin model was developed for tactile evaluation systems and for robots that have physical contact with humans $[15,16]$. The surface of this counterpart specimen had $0.15 \mathrm{~mm}$ deep grooves at a $0.5 \mathrm{~mm}$ pitch in order to imitate fingerprints. The artificial skin specimen was developed so as to be used in the development of tactile evaluation systems for robots that come into physical contact with humans $[15,16]$.

The artificial skin specimen was fixed onto the balance arm of the friction tester, on which a load cell was attached. The samples were tested as a pair, and they were folded in the middle while the one side of them was fixed with a jig to

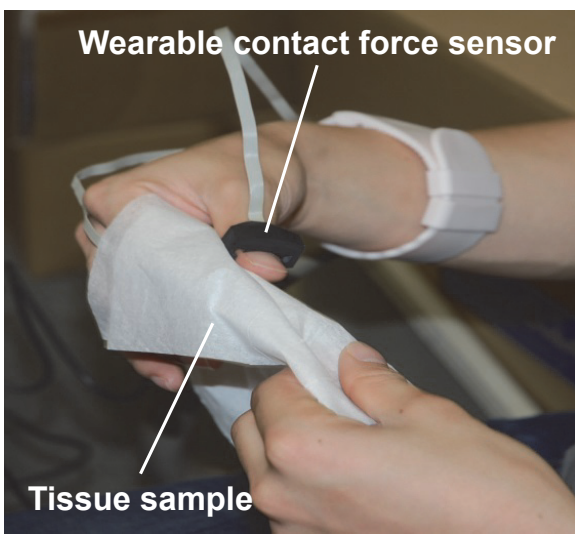

Fig. 4 Experiment image of measuring movement velocities of subject's fingers and forces at sensory test 
Table 3 (a) Movement velocities and (b) pressing forces of five subjects

(a)

\begin{tabular}{|c|c|c|c|c|}
\hline \multirow{2}{*}{ Subject } & \multicolumn{2}{|c|}{ Velocity of thumb $\mathrm{v}, \mathrm{mm} / \mathrm{s}$} & \multicolumn{2}{c|}{ Velocity of Index finger, $\mathrm{mm} / \mathrm{s}$} \\
\cline { 2 - 5 } & Maximum & Average & Maximum & Average \\
\hline I & 11.76 & 4.82 & 13.72 & 4.46 \\
\hline II & 15.68 & 4.24 & 14.80 & 5.83 \\
\hline III & 14.70 & 6.51 & 17.20 & 7.12 \\
\hline IX & 10.78 & 3.74 & 10.78 & 5.03 \\
\hline X & 12.74 & 5.88 & 14.70 & 7.50 \\
\hline
\end{tabular}

(b)

\begin{tabular}{|c|c|c|c|c|}
\hline \multirow{2}{*}{ Subject } & \multicolumn{2}{|c|}{ Force of thumb, $\mathrm{N}$} & \multicolumn{2}{|c|}{ Force of index finger, $\mathrm{N}$} \\
\hline & Maximum & Average & Maximum & Average \\
\hline I & 0.73 & 0.23 & 1.33 & 0.47 \\
\hline II & 0.91 & 0.32 & 0.85 & 0.52 \\
\hline III & 1.10 & 0.51 & 1.26 & 0.60 \\
\hline IX & 0.94 & 0.33 & 1.08 & 0.35 \\
\hline$X$ & 1.40 & 1.03 & 1.16 & 0.89 \\
\hline
\end{tabular}
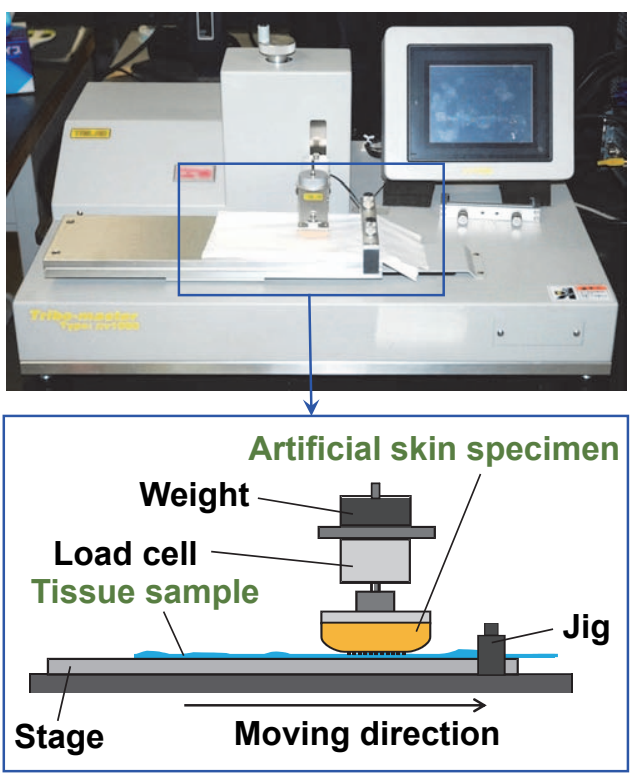

Fig. 5 Linear-motion friction tester

the underlying stage. Before being placed into contact with a sample, the surface of the artificial skin specimen was cleaned with an unwoven cotton that had been soaked in a cleaning liquid before being left to dry in the air. The other side of the folded sample was pulled out in order to smooth it out, and then the artificial skin was put into contact with the sample that was to be tested. A normal load was applied with a weight made of steel. The underlying stage was then moved in a single direction, and the friction force was measured by the load cell. The friction coefficient was calculated as a ratio of the friction force to the normal load.

Table 4 lists the conditions of the friction test. In accordance with the results from the wearable contact force tests, we used the normal loads of $0.098,0.49$, and $0.98 \mathrm{~N}$. Additionally, we used the sliding velocities of 1, 10, and $50 \mathrm{~mm} / \mathrm{s}$. Friction forces were only applied in one direction. The sliding distances were $5 \mathrm{~mm}$ at $1 \mathrm{~mm} / \mathrm{s}, 15 \mathrm{~mm}$ at $10 \mathrm{~mm} / \mathrm{s}$, and $50 \mathrm{~mm}$ at $50 \mathrm{~mm} /$ s. We repeated each test 15 times under the same conditions. Before the friction tests, the samples were put into the room where testing would be conducted 24 hours prior to testing at a temperature of $25 \pm 1^{\circ} \mathrm{C}$ and humidity of $20 \pm 1 \%$ (as was used for the sensory tests).
Table 4 Friction test conditions

\begin{tabular}{|l|c|}
\hline \multirow{2}{*}{ Sample } & $\begin{array}{c}\text { Ten different kinds of facial } \\
\text { tissues commercially available } \\
\text { in Japan }\end{array}$ \\
\hline Counterpart specimen & Artificial skin specimen \\
\hline \multirow{3}{*}{ Normal load $W, \mathrm{~N}$} & 0.098 \\
\cline { 2 - 2 } & 0.49 \\
\hline \multirow{3}{*}{ Sliding velocity $v, \mathrm{~mm} / \mathrm{s}$} & 0.98 \\
\cline { 2 - 2 } & 1.0 \\
\hline Sliding distance $L, \mathrm{~mm}$ & 10 \\
\hline $\begin{array}{l}\text { Number of repetition } \text { under } \\
\text { the same condition } N, \text { times }\end{array}$ & 50 \\
\hline Test room temperature $T,{ }^{\circ} \mathrm{C}$ & 5 \\
\hline Test room humidity $R H, \% \mathrm{RH}$ & 15 \\
\hline
\end{tabular}

\section{Results and discussion}

3.1 Evaluation scores of the facial tissues in the sensory tests

Figure 6 presents the images of how the subject tested the samples in the sensory tests. Whereas the subjects were instructed to touch the samples in any way they liked, most of them evaluated the samples through one of two ways: by blowing their nose into it or by wiping their hand with it. The time taken to evaluate a sample was unspecified; while some of them spent several tens of seconds evaluating a sample, others finished in only a few seconds.

Figure 7 depicts the scores of the subjects' evaluations of the samples in the sensory tests. The error bars indicate the
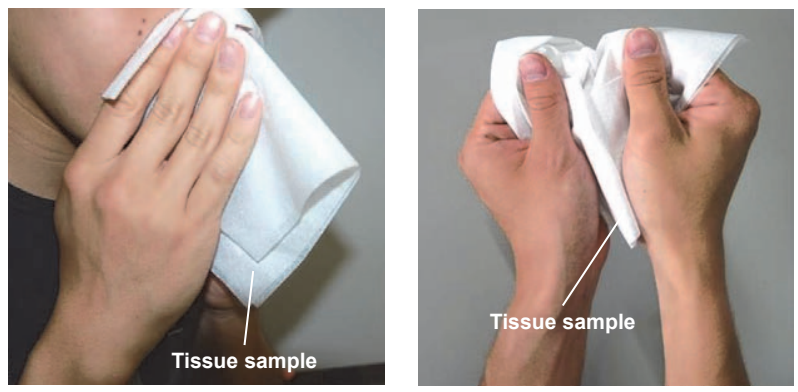

Fig. 6 Images of how subject tested samples in sensory tests 


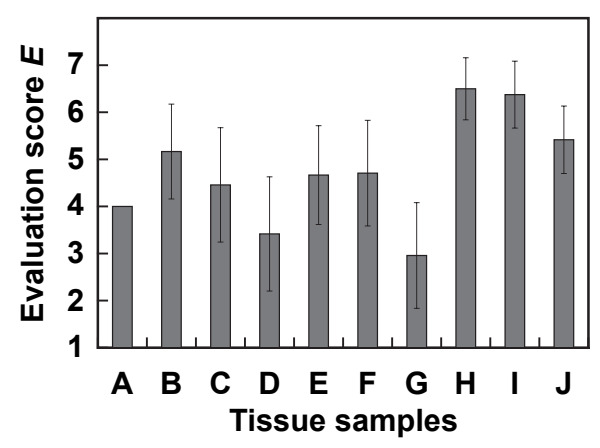

Fig. 7 Scores of subjects' evaluations of tissue samples in sensory tests

standard deviation of the scores collected under the same test conditions, and the columns show the average values. Samples B, C, E, F, H, I, and J were all scored higher by the subjects than sample A (i.e., the standard sample, score 4 must be obtained necessarily). The highest score that was achieved was for sample $H$, which was 6.5. Contrastingly, samples D and G got lower scores than A, with the lowest score of 3 being awarded to sample G. Therefore, the maximum difference between all of the samples was 3.5 point, which indicates that the textural characteristics of the samples were quite different.

\subsection{Friction coefficients of the facial tissues}

Figure 8 depicts the friction coefficient as a function of time at a normal load of $0.49 \mathrm{~N}$ and a sliding velocity of $1 \mathrm{~mm} / \mathrm{s}$; these were the values obtained for samples B, G, and $\mathrm{H}$. The friction coefficient increased during the initial stages of the application of the friction force, but it subsequently moved into a steady state. The increases in the initial stage may have been caused by the deformation of the artificial skin used in the tests as well as the extension of the tested sample. Fluctuations in the steady state, like a stick-slip motion, may have been caused by the crepes or holes that appeared on the surface of the samples. Between 4 and $5 \mathrm{~s}$, sample $\mathrm{G}$ was found to have a high friction coefficient, while that of sample $\mathrm{H}$ was low at this time. Furthermore, the changes of the friction coefficients in the frequency and amplitude for sample $G$ were large.

The relationship between the mean friction coefficient and the sliding velocity is shown in Fig. 9. The mean friction coefficient was calculated between 4 and $5 \mathrm{~s}$. The friction coefficient was found to decrease as the sliding velocity decreased at loads of 0.098 and $0.49 \mathrm{~N}$; this decrease may have caused the samples to

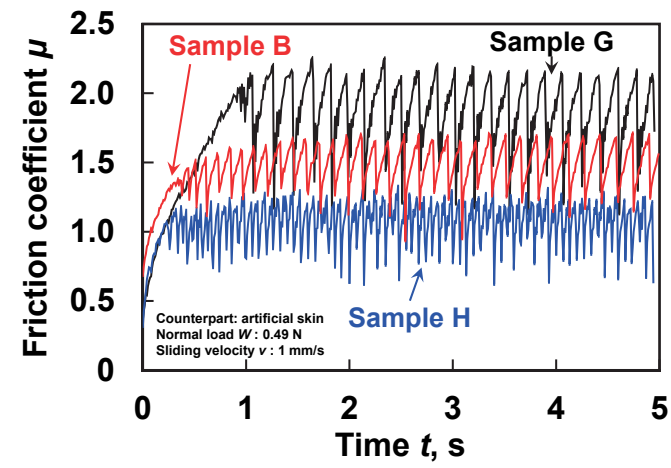

Fig. 8 Friction coefficient as a function of time at a normal load of $0.49 \mathrm{~N}$ and a sliding velocity of $1 \mathrm{~mm} / \mathrm{s}$ for samples B, $\mathrm{G}$, and $\mathrm{H}$ stick to or slip from the tested surface. Sample A, as the standard, exhibited intermediate values when compared to the other testes samples. Samples H and I, which contained moisturizing agents, were found to have the low friction coefficients. In addition, the gradients of the $\mu_{\mathrm{m}}-v$ relationship for samples $\mathrm{H}$ and I were gentle. The standard deviations of the mean friction coefficients found for the groups of samples collected under the same test conditions are listed in Table 5. Samples C, D, and G, which were found to have high friction coefficients, were also found to have a wide range of values.

3.3 Multiple regression analysis for the evaluation score

In order to investigate the factors affecting the textural

(a)

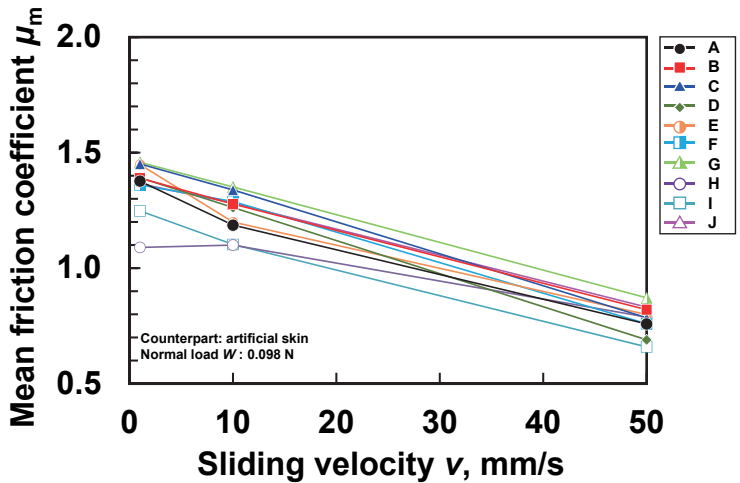

(b)

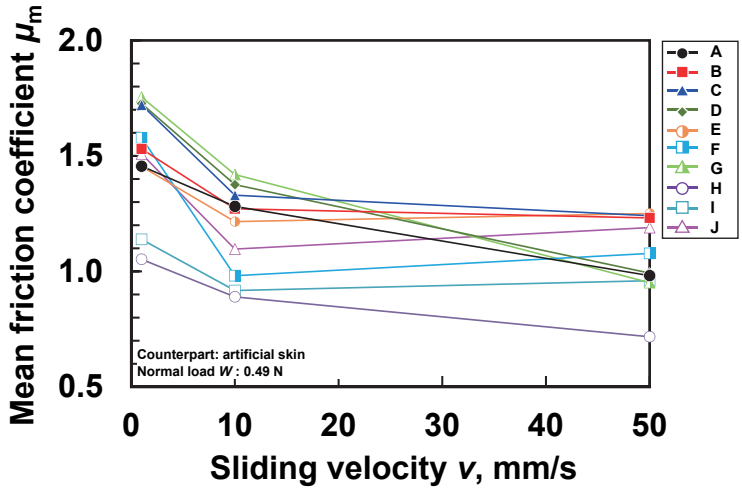

(c)

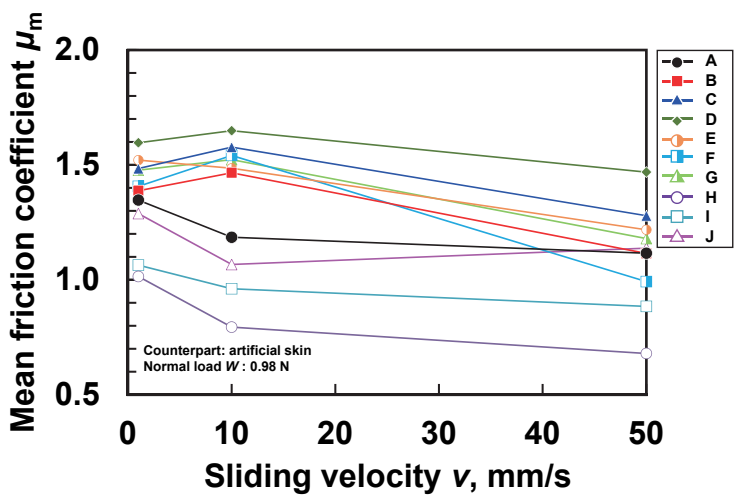

Fig. 9 Relationship between mean friction coefficient and sliding velocity at normal load of (a) $0.098 \mathrm{~N}$, (b) $0.49 \mathrm{~N}$, and (c) $0.98 \mathrm{~N}$ 
Table 5 Standard deviation of mean friction coefficient found for group of samples collected under the same test conditions

\begin{tabular}{|c|c|c|c|c|c|c|c|c|c|}
\hline$W, \mathrm{~N}$ & 0.098 & 0.098 & 0.098 & 0.49 & 0.49 & 0.49 & 0.98 & 0.98 & 0.98 \\
\hline$v, \mathrm{~mm} / \mathrm{s}$ & 1 & 10 & 50 & 1 & 10 & 50 & 1 & 10 & 50 \\
\hline Sample A & 0.13 & 0.19 & 0.17 & 0.07 & 0.12 & 0.11 & 0.08 & 0.10 & 0.06 \\
\hline Sample B & 0.15 & 0.14 & 0.15 & 0.04 & 0.14 & 0.06 & 0.10 & 0.09 & 0.03 \\
\hline Sample C & 0.15 & 0.15 & 0.17 & 0.16 & 0.19 & 0.12 & 0.10 & 0.18 & 0.16 \\
\hline Sample D & 0.14 & 0.23 & 0.09 & 0.16 & 0.22 & 0.17 & 0.14 & 0.16 & 0.20 \\
\hline Sample E & 0.21 & 0.15 & 0.15 & 0.06 & 0.11 & 0.13 & 0.09 & 0.17 & 0.07 \\
\hline Sample F & 0.13 & 0.09 & 0.19 & 0.09 & 0.10 & 0.10 & 0.10 & 0.17 & 0.16 \\
\hline Sample G & 0.17 & 0.23 & 0.17 & 0.14 & 0.19 & 0.22 & 0.14 & 0.25 & 0.20 \\
\hline Sample H & 0.13 & 0.09 & 0.22 & 0.06 & 0.08 & 0.05 & 0.06 & 0.15 & 0.05 \\
\hline Sample I & 0.14 & 0.15 & 0.11 & 0.15 & 0.12 & 0.10 & 0.09 & 0.14 & 0.06 \\
\hline Sample J & 0.12 & 0.11 & 0.13 & 0.13 & 0.16 & 0.16 & 0.10 & 0.13 & 0.06 \\
\hline
\end{tabular}

Table 6 Results of multiple regression analysis on scores obtained in the sensory tests

Model summary

\begin{tabular}{|c|c|c|}
\hline $\mathrm{R}$ & Adjusted R square & Standard error of the estimate \\
\hline 0.88 & 0.74 & 0.59 \\
\hline
\end{tabular}

Analysis of variance

\begin{tabular}{|c|c|c|}
\hline Sum of squares & F & Significance probability \\
\hline 9.2 & 26.63 & $<0.05$ \\
\hline
\end{tabular}

Coefficients

\begin{tabular}{|c|c|c|c|}
\hline & $\begin{array}{c}\text { Unstandardized partial } \\
\text { regression coefficient }\end{array}$ & $\mathrm{t}$ & Significance probability \\
\hline Constant & 11.25 & 8.86 & $<0.05$ \\
\hline Mean friction coefficient $\quad \mu_{\mathrm{m}}$ & -4.32 & -5.16 & $<0.05$ \\
\hline
\end{tabular}

characteristics of the facial tissues, we used a multiple regression analysis on the scores obtained in the sensory tests. The dependent variable in the analysis was the evaluation score, and the independent variables were the eleven mechanical properties listed in Table 1 and the mean friction coefficients obtained for each test condition. A stepwise method was used in the analysis using SPSS® 19.0 for Windows (SPSS Inc., Chicago, IL, USA). We found that the highest value of the adjusted coefficient of determination was obtained for a normal load of $0.49 \mathrm{~N}$ and a sliding velocity of $1 \mathrm{~mm} / \mathrm{s}$. The analysis results are shown in Table 6. Surprisingly, the mean friction coefficient remained alone as an independent variable; the other properties were removed. We found that the friction coefficient was the parameter that was best suited for predicting a score that a sample would receive in the sensory test. From the analysis, we obtained a regression formula with a 0.74 coefficient of determination as follows:

$$
E=-4.32 \mu_{\mathrm{m}}+11.25
$$

The relationship between the evaluation scores and the mean friction coefficients is depicted in Fig. 10. The evaluation score was found to correlate negatively with the mean friction coefficient (the correlation coefficient was -0.88 ). We therefore concluded that, in order for a facial tissue to be considered to have good textual characteristics, it is important for its friction to be reduced.

3.4 Relationship between mechanical properties of facial tissues and their friction coefficients

In order to develop low friction facial tissues, the relationship between the friction coefficient and the mechanical properties needs to first be clarified. The correlation between the mean friction coefficient at the normal load of $0.49 \mathrm{~N}$ and

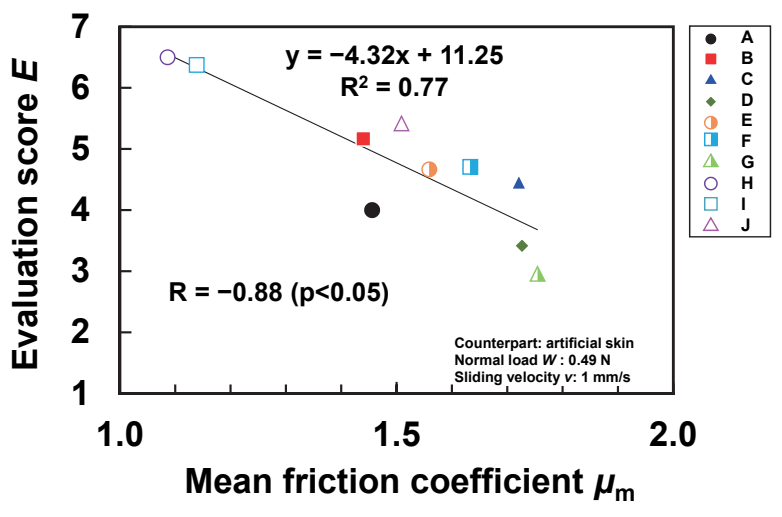

Fig. 10 Relationship between evaluation score and mean friction coefficient

the sliding velocity of $1 \mathrm{~mm} / \mathrm{s}$ and the mechanical properties of the samples is shown in Table 7. The mean friction coefficient shows a strong negative correlation with moisture content $(\mathrm{R}=$ -0.79 ) and a strong positive correlation with the tensile strength perpendicular to the fiber direction in dry facial tissues $(R=0.80)$. We also found that a moisturizing agent that has a high water content can act as a lubricant, thereby resulting in low friction. In order to reduce friction, we propose that the moisture content of a facial tissue should be increased while the tensile strength perpendicular to the fiber direction in dry tissues should be decreased. However, too much moisture can cause degradation in the strength of a facial tissue, resulting in tissue tearing. Furthermore, if there is a too great decrease in the tissue's strength due to any particular characteristics, then tearing will occur. It is therefore important to balance the friction properties of a facial tissue with the mechanical properties.

In addition, the tissues that did not have any moisturizing 
Table 7 Correlation coefficients between mean friction coefficient at a normal load of $0.49 \mathrm{~N}$ and a sliding velocity of $1 \mathrm{~mm} / \mathrm{s}$ and the mechanical properties

\begin{tabular}{|c|c|c|}
\hline & Correlation coefficient $R$ & $\begin{array}{c}\text { Significance probability } \\
p\end{array}$ \\
\hline Moisture content $\alpha, \%$ & -0.79 & $<0.05$ \\
\hline Density $\rho, \mathrm{kg} / \mathrm{m}^{3}$ & -0.09 & 0.81 \\
\hline Paper thickness $t, \mu \mathrm{m}$ & -0.45 & 0.19 \\
\hline Tensile strength along to fiber direction in $\operatorname{dry} \sigma_{\mathrm{da} r} \mathrm{~N}$ & 0.62 & 0.06 \\
\hline Tensile strength perpendicular to fiber direction in dry $\sigma_{\mathrm{dp}} \mathrm{N}$ & 0.80 & $<0.05$ \\
\hline Tensile strength perpendicular to fiber direction in wet $\sigma_{\mathrm{wp}} \mathrm{N}$ & -0.40 & 0.26 \\
\hline Softness $s, \times 10^{-2} \mathrm{~N}$ & 0.50 & 0.14 \\
\hline Surface roughness $R_{a} \mu \mathrm{m}$ & 0.02 & 0.95 \\
\hline Surface waviness $W_{a} \mu \mathrm{m}$ & -0.65 & $<0.05$ \\
\hline Compressive elastic modulus $E, \mathrm{kPa}$ & 0.08 & 0.83 \\
\hline Mean fiber diameter $d_{\mathrm{m}}, \mu \mathrm{m}$ & 0.02 & 0.95 \\
\hline
\end{tabular}

agents (samples $A-G$ ) were thought to have similar shear strengths at the interface between themselves and the artificial skin; this similarity was caused by the low moisture content in all these samples. In the adhesion theory [17], a friction force depends on the shear strength, contact area, and a plowing term; it can be written as the following Eq.:

$$
F=\tau \cdot A_{\mathrm{r}}+p_{\mathrm{e}}
$$

where, $\tau$ is the shear strength $(\mathrm{Pa}), A_{\mathrm{r}}$ is the real contact area $\left(\mathrm{m}^{2}\right)$, and $p_{\mathrm{e}}$ is the plowing term $(\mathrm{N})$. The plowing term is often replaced by a hysteresis loss when the frictional material is a viscoelastic body. As such, the friction coefficient of samples examined can be considered to be functions of the contact area and the normal load. However, observing and measuring the contact area during sliding is exceedingly difficult, because of the permeability of the fibers and the complicated threedimensional structure of the samples (i.e., they possess a discontinuous surface). Greenwood and Williamson proposed that a contact interface between the surfaces that have a profile followed by a Gaussian or exponential distribution has a linear relationship between the normal load and the contact area, irrespective of the elastic or plastic contact [18]. The relationship can be expressed as in the following Eq.:

$$
A=\frac{\pi^{\frac{1}{2}}}{E^{*}}\left(\frac{\beta}{\sigma^{*}}\right)^{\frac{1}{2}} W
$$

where $A$ is the total contact area $\left(\mathrm{m}^{2}\right), E^{*}$ is the equivalent elastic modulus $(\mathrm{Pa}), \beta$ is the curvature radius of the surface asperity $(\mathrm{m}), \sigma^{*}$ is the standard deviation of the asperity height $(\mathrm{m})$, and $W$ is the normal load $(\mathrm{N})$. It can be assumed here that (a) the samples have surfaces with Gaussian distributions, (b) the mean curvature radius of the surface asperity is equal to half the mean fiber diameter, and (c) the standard deviation of the asperity height has a linear relationship with the surface roughness. By using these assumptions and Eqs. (3) and (4), we can obtain the friction coefficient:

$$
\mu=k \frac{1}{E^{*}}\left(\frac{d_{\mathrm{m}}}{2 R_{\mathrm{a}}}\right)^{\frac{1}{2}}+\frac{p_{\mathrm{e}}}{W}
$$

where, $k$ is a constant, $d_{\mathrm{m}}$ is the mean diameter of the fiber $(\mathrm{m})$, and $R_{\mathrm{a}}$ is the surface roughness (m). Figure 11 shows the relationship between the mean friction coefficient and the variables in the first term of the Eq. (5). The coefficient of determination of the relationship was high $\left(R^{2}=0.67\right)$. Although the approximation expression had an intercept (i.e., it did not through the origin),

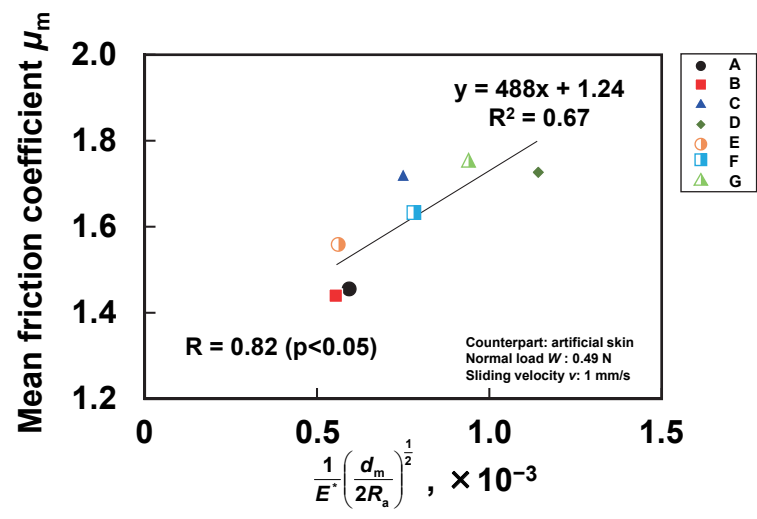

Fig. 11 Relationship between mean friction coefficient and variables in first term of Eq. (5)

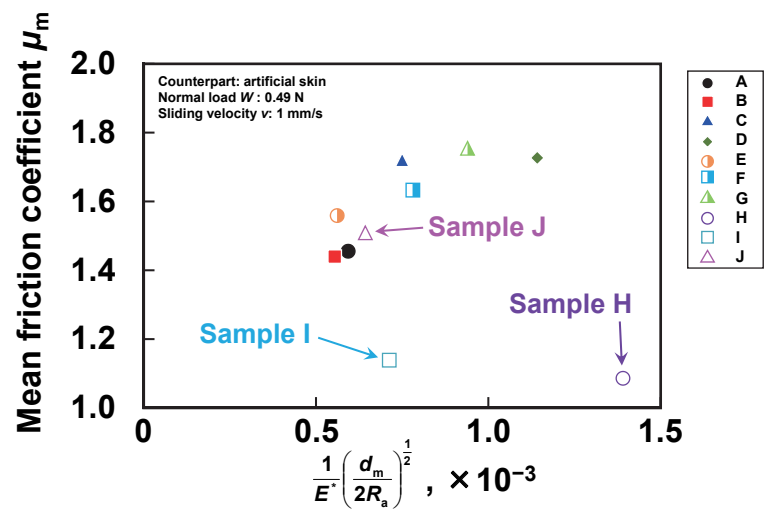

Fig. 12 Relationship between mean friction coefficient (all the samples) and variables in first term of Eq. (5)

which was thought to have been derived from the hysteresis loss between the artificial skin and the samples, it can be said that the mean friction coefficient was found to be influenced by the elastic modulus, fiber diameter, and surface roughness. Our results indicate that increasing the elastic modulus and surface roughness of a facial tissue and decreasing the fiber diameter are all effective ways for reducing the friction coefficients of facial tissues when no moisturizing agents are used.

Figure 12 depicts the relationship between the mean friction coefficient of the non-moisturized and moisturized tissue papers and the variables. The facial tissues with moisturizing 
agents did not match the approximation line in Fig. 11 excepting sample J. This indicated that the shear strengths of sample $\mathrm{H}$ and I were quite different from those of the tissues that did not have any moisturizing agents. The moisturizing agents strongly affected a friction behavior of facial tissues. The friction coefficient of sample J closed to the approximation line; the shear strength of sample J may be close to those of the tissues without any moisturizing agents.

In Fig. 8, the fluctuation of the friction coefficient appeared; the periodic width of friction coefficient and the gap between frictional vibration had strong positive correlation to the tensile strength $(R=0.80$ and 0.90 , respectively). However, these parameters did not have strong correlation to the evaluation score ( $R=-0.43$ and -0.55 , respectively). Thus, human skin presumably did not perceive the stick-slippy motion in the present tests.

\section{Conclusions}

In the current study, we conducted sensory tests for facial tissues that are commercially available in Japan, and we also tested the friction generated by the rubbing of these tissues on an artificial skin model. Using these results, we investigated the factors affecting the textural characteristics of the facial tissues. The conclusions deduced in this study are as follows:

(1) Sample H, which contained a moisturizing agent, had the highest evaluation score among the samples.

(2) The friction coefficients of the samples increased during the initial stages of a friction force being applied, but it settled into a steady state barring minor localized variations. The mean friction coefficient decreased as the sliding velocity decreased for low normal loads. Samples H and I, which contained moisturizing agents, had the low friction coefficients.

(3) From the multiple regression analysis, the highest value of the adjusted coefficient of determination was obtained when including the results for a normal load of $0.49 \mathrm{~N}$ and a sliding velocity of $1 \mathrm{~mm} / \mathrm{s}$. Surprisingly, the mean friction coefficient was the only parameter that could be used to predict the evaluation scores; the evaluation score correlated negatively with the mean friction coefficient.

(4) In order to reduce the friction, one should seek to increase the moisture content of a facial tissue or decrease the tensile strength perpendicular to the fiber direction in dry facial tissues; however, this allows tearing of the tissues to occur more readily.

(5) Increasing the elastic modulus and surface roughness and decreasing the fiber diameter were found to be effective methods for reducing the friction coefficient of facial tissues that did not contain moisturizing agents.

\section{Acknowledgement}

The authors thank Mr. Shohei Matsumura for his help in the sensory and friction tests.

\section{References}

[1] Stelte, W. and Sanadi, A. R., "Preparation and Characterization of Cellulose Nanofibers from Two Commercial Hardwood and Softwood Pulps," Industrial \& Engineering Chemistry Research, 48,

\section{4, 2009, 11211-11219.}

DOI: 10.1021/ie9011672

[2] Washiyama, H., "Evaluation Methods of Facial Tissues," Japan Tappi Journal, 40, 7, 1986, 605-612 (in Japanese). DOI: $10.2524 /$ jtappij.40.605

[3] Skedung, L., Danerlöv, K., Olofsson, U., Aikala, M., Niemi, K., Kettle, J. and Rutland, M. W., "Finger Friction Measurements on Coated and Uncoated Printing Papers," Tribology Letters, 37, 2, 2010, 389-399. DOI: 10.1007/s11249-009-9538-z

[4] Giboreau, A., Navarro, S., Faye, P. and Dumortier, J., "Sensory Evaluation of Automotive Fabrics: The Contribution of Categorization Tasks and non Verbal Information to Set-up a Descriptive Method of Tactile Properties," Food Quality and Preference, 12, 5-7, 2001, 311-322. DOI: 10.1016/S0950-3293(01)00016-7

[5] Philippe, F., Schacher, L., Adolphe, D. C. and Dacremont, C., “Tactile Feeling: Sensory Analysis Applied to Textile Goods," Textile Research Journal, 74, 12, 2004, 1066-1072. DOI: 10.1177/004051750407401207

[6] Pense-Lheritier, A. M., Guilabert, C., Bueno, M. A., Sahnoun, M. and Renner, M., "Sensory Evaluation of the Touch of a Great Number of Fabrics," Food Quality and Preference, 17, 6, 2006, 482-488. DOI: 10.1016/j.foodqual.2005.06.002

[7] Suelar, V. and Okur, A., "Sensory Evaluation Methods for Tactile Properties of Fabrics," Journal of Sensory Studies, 22, 1, 2007, 1-16. DOI 10.1111/j.1745-459X.2007.00090.x

[8] Cho, G., Casali, J. G. and Yi, E., "Effect of Fabric Sound and Touch on Human Subjective Sensation," Fibers and Polymers, 2, 4, 2001, 196-202. DOI: 10.1007/BF02875345

[9] Na, Y. and Kim, C., "Quantifying the Handle and Sensibility of Woven Silk Fabrics," Textile Research Journal, 71, 8, 2001, 739-742. DOI: 10.1177/004051750107100814

[10] Japanese Standards Association, JIS P 8135:1998, Paper and Board Determination of Tensile Strength After Immersion in Water (in Japanese).

[11] Japanese Standards Association, JIS P 8113:2006, Paper and Board Determination of Tensile Properties Part 2: Constant Rate of Elongation Method (in Japanese).

[12] Japanese Standards Association, JIS P 8127:2010, Paper and Board Determination of Moisture Content of a Lot-Oven-Drying Method (in Japanese).

[13] Japanese Standards Association, JIS L 1096:2010, Testing Methods for Woven and Knitted Fabrics (in Japanese).

[14] Osgood, C. E., "Semantic Differential Technique in the Comparative Study of Cultures," American Anthropologist, 66, 3, 1964, 171-200. DOI: 10.1525/aa.1964.66.3.02a00880

[15] Kuramitsu, K., Nomura, T., Nomura, S., Maeno, T. and Nonomura, Y., "Friction Evaluation System with a Human Finger Model," Chemistry Letters, 42, 3, 2013, 284-285. DOI: 10.1246/cl.2013.284

[16] Shirado, H., Nonomura, Y. and Maeno, T., "Development of Artificial Skin Having Human Skin-like Texture,"Transactions of the Japan Society of Mechanical Engineers Series C, 73, 726, 2007, 541-546 (in Japanese).

DOI: 10.1299/kikaic.73.541

[17] Bowden, F. P. and Tabor, D., "The Friction and Lubrication of Solids," Pt II. Oxford University Press, 1964, 90-121.

[18] Greenwood, J. A. and Williamson, J. B. P., “Contact of Nominally Flat Surfaces," Proceedings of The Royal Society A; Mathematical, Physical and Engineering Sciences, 295, 1442, 1966, 300-319. DOI: 10.1098/rspa.1966.0242 